Patricia ȘOITU

Faculty of Letters, Ovidius University

Constanța, Romania

soitu.patricia@gmail.com

\title{
FOOD PORN AT THE CROSSROADS: BETWEEN POSTMODERNISM AND DIGIMODERNISM IN STEPHANIE SARLEY'S (UN)ORTHODOX VISUAL ART
}

Recommended Citation: Şoitu, Patricia. "Food Porn at the Crossroads: Between Postmodernism and Digimodernism in Stephanie Sarley's (Un)orthodox Visual Art.” Metacritic Journal for Comparative Studies and Theory 5.2 (2019): https://doi.org/10.24193/mjcst.2019.8.07

\begin{abstract}
Since its emergence in the late 1990s, the cultural paradigm of digimodernism has been regarded as a hybrid product, born out of postmodernism's toxic ashes. Meant both as a partial continuation and as a reaction against its monolithic predecessor, digimodernism brought to light Lyotard's ambivalent legacy of the grand narratives and sought to demonstrate their actuality, despite the few muffled screams of irony and ambiguity, found at the dying heart of postmodernity. Alternatively, the postmodern is seen as a space where capitalism does not necessarily suppress the possibility of emancipation, by means of the Web 2.0-based technology and where it does not always amount to efficiency and profit. By looking at Stephanie Sarley's art, I will attempt not only to conceptualize and illustrate industrial pornography as a metanarrative, with regard to the type of food porn the artist creates, but also to elaborate on the uninterrupted connection between digimodern and postmodern features reflected in her prototypic art and exemplify how the former comes to be inscribed as a technological facet of the latter. The endless narrative form sheds light on a process of alienation from the basic goal of the prescribed mechanisms found at the core of the pornographic industry and labels the metanarrative of
\end{abstract}


Judeo-Christianity as oppressive, against freedom and democracy, while the metanarrative of capitalism is almost reduced to non-existence through Sarley's altogether purely emancipatory, digimodern and postmodern artwork.

Keywords: postmodernism, digimodernism, food porn, metanarrative, gaze

\section{A Short Overview of "Food Porn"}

"among other practices, gender inequality becomes both sexual and socially real" - Catherine Mackinnon, "Sexuality, Pornography, and Method: «Pleasure under Patriarchy»" (1989, 328)

An online trend that has evolved and has recently accelerated is defined by the presence of women in the blogosphere, in various domains, from motherhood, sports, business, fashion, to the culinary and artistic fields. In what follows, I will focus on the analysis of one such online female presence, Stephanie Sarley's ${ }^{1}$, who, through her feminist artwork, strays from the primary meanings of food porn discussed below, throwing a postmodern challenge in the face of the oppressive and totalizing discourses of pornography, religion and patriarchy, by playfully making use of one such digital platform, in order to disseminate her feminist ideas. I will also attempt to provide a "solution" so as to transcend such rigid and dictatorial institutions, a way out, a way which starts from each woman, one that is neither radical, nor liberal, but a long overdue interweaving of the two antipodean feminisms.

If flamed bananas are the norm, how about a sectioned kiwi with oozing yoghurt on top and a finger or two piercing in-between its juicy halves? Alexander Cockburn's 1977 coinage of gastro-porn - in a French cookbook review - to describe food that "heightens the excitement and also the sense of the unattainable", and his following understatement that "the delights offered in sexual pornography are equally unattainable" (Cockburn 125) should address my visually aesthetic and viscerally rhetorical inquiry. In 1979, the term food porn is

${ }^{1}$ Stephanie Sarley is "a prolific multimedia artist creating her own world of art, using humor and absurdity to boldly challenge how sexuality is perceived and defined. Her art encompasses the surreal and the visceral. Through her current works she is redefining how people look at food" [http://stephaniesarley.com/]. 
used antithetically by Michael Jacobson, in the Nutrition Action Healthletter of the Center for Science in the Public Interest, to oppose Right Stuff and to differentiate between healthy and unhealthy foods. The terms have been used conjointly throughout the 1980 s and 1990s and have been assigned several pseudo-artistic meanings and connotations, each gradually devaluing and surpassing the other as time passed, resulting in the usage of food-porn as the most casually employed of the two, from the 200os onward: "food porn gained its initial linguistic tradition in the 1980 s and accelerated throughout the 1990 and 2000 s to attain its present vaunted status" (McBride 41).

Initially, "food porn" belonged to the denotative sphere of food preparation, in the sense that it used to refer to a well-done plating of expensive ingredients, a habitus ${ }^{2}$, a social hint of those who afforded such dishes, usually people belonging to the upper and middle classes. With the emergence of technology and digital reproduction, which were influenced by the rapid expansion of capitalism, the term started to acquire more homogenous connotations, either referring to the host of a cooking show on TV, usually a female, licking chocolate off her fingers or having gravy licked off by a male cohost, as part of the tasting and entertainment processes, or a multilayered chocolate cake with sprinkles and topping, slowly dripping off its neither too hard, nor too soft crust: "it was only a matter of time before a desire as essential and physical as food would be co-opted by capitalism's most profitable avenues of distribution and sales" (McBride 41).

Whether we think of caviar, oysters, saffron or kobe beef, such a fancy spoon-feeding of the senses clearly alludes to and even displays the financial potency of upper and middle classes, given that lower class citizens did not have access to suchlike ingredients, not even visually. Even nowadays, such culinary orgasms are not part of everyone's daily or weekly meals but are reserved for a small percentage of people who possess the monetary resources to exhaust, in order to satisfy their refined appetites. Moreover, being able to take photographs

${ }^{2}$ I refer to habitus as the conditions which owe to class bias depicted in Pierre Bourdieu's Distinction. A Social Critique of the Judgement of Taste (1984): "the systems of dispositions (habitus) characteristic of the different classes and class fractions (...) the internalized form of class condition and of the conditionings it entails" (Bourdieu 6, 118). 
of such food demands extensive plans, skills and immediacy, so as the dish parades as fresh and mouth-watering, in order to elicit and intensify the longing for the unachievable, while transferring it onto the viewer still hot, subsequently creating a rush for carnal gratification.

In most of the cases, the collective enjoyment and visual consumption of the soon-to-be dish is assured by its diffusion through technological means. As one clearly observes when watching cooking shows, there is a specially designed stage which resembles our ideal kitchen and fuels the desire to try such recipes on our own, at home. What is more, as far as female chefs are concerned, they are rarely cooking by themselves, being accompanied by a male chef or host and possibly having sauce licked off their index fingers. Such inappropriate allusions to sexuality had multiplied with the development of visual media while, in turn, these shows aimed to attract audiences and satisfy both their visual and visceral cravings, to the extent that spectators were left with an illusory aftertaste of the unattainable, of that particular dish they could not taste, but only yearn with gaping mouths. Tantalizing actions are aimed towards a large audience, including both males and females who satisfy not only their food cravings, but also their sexual appetite by watching the show: "audiences co-constitute the pornographic gaze" (McDonnell 254).

Furthermore, a parallel can be drawn between the bourgeois delicacies and TV cooking shows, knowing that lobster-like ingredients were totally hidden from both the view and the taste buds of the lower classes, whereas the dishes and gender relations that cooking shows present us with are accessible to a wide range of individuals, due to media expansion and affordability. Media, along with capitalism, has been able to render visual access equal for all individuals, not only for society's crème, thus enabling the individuals' access to the VIP area of prosumerism and demystifying the optical. Consequently, it contributed to the development of a new frustration and an even worse craving among those who cannot surpass material difficulties: "food porn in the hands of capitalism sought to create a consumption community through desire for new offerings on the market" (Ibrahim 7). Because of the technological advances, not only the pornographic field became more popular, but also the gastronomic field: 
Highly aesthetic food becomes the unattainable object of desire, consumed primarily through the eyes and mind. Like sexual pornography, gastropornography teases the line of unattainability, tantalizing the audience to believe that they could do that, have that. (McDonnell 242)

Thus, a link between the two was inevitably established, even though at a subconscious level, both by chefs and audiences. The imagined picture of a brick street chocolate cake - just one of the many available online where, besides the thickness and viscosity of the cake, the lack of the slice, as well as the hole in the middle generate a suggested castration of the cake. In the same image, a "feminization" of the object that is the cake happens when its cocoa filled folds, a range of concentric sculptures are moisturized by thick chocolate sauce, an ooze which very much resembles not only the feminine bodily liquids in its consistence (birth milk, period blood, vaginal discharge, arousal fluid and cervical mucus), but also the semen eliminated during the male ejaculation. In the final analysis of the image, the sauce leaking all over the cake's layers, triumphantly rejoicing in its masculinity, accounts for Susan Faludi's view that "all porn scenes should end with a visible ejaculation" (Faludi qtd. in Chan 52).

As I have shown above, "food porn," in its initial $20^{\text {th }}$ century unbound track, could either designate "still or moving images of food/or eating across various media, including cookbooks, magazines, television, blogs, websites" or "the person or people preparing or eating the food" (Rousseau 748). Due to the lack of performativity, this ceaseless desiring would have been expressed through eating, if such a debauchery were equally possible for every individual back in the midst of the upper class' ruling and bourgeoisie's ascendancy. Therefore, in the 1980 s and 1990s, food porn becomes a new type of pornography; it turns from something which, for most people, used to be neither attainable, nor practical, into something else, which is visually and sometimes viscerally attainable, but only occasionally practical and resourceful, since it is consumed by playfully making use of one's other senses. 
At the same time, the association between the two terms, food and porn, has been negatively looked upon, despite its complicitous and subversive attributes provided for empowering women and asserting female agency through the metaphorical staging of hypersexuality and heteronormative domesticity. For instance, Krishnendu Ray (40) argues that "[o]nce you call something pornographic, you bring down moral opprobrium on it. You poison the topic and stop the discussion”. Similarly, Alan Madison (40) denounces the usage of porn in conjunction with food: "to single out food for this pejorative is disingenuous and hypocritical". Such counter-arguments can be very easily and silently put to sleep by stating that both the term of porn and its physical implications entail a more pleasurable, empowering and self-aggrandizing dimension especially for men: "the experience of watching porn endows men with feelings of confidence, acceptance and the absence of anxiety" (Garlick 13), thence men cast away the fear(s) of no longer being in charge, by visually and physically engaging in the pornographic realm. These acts are no good, from my point of view, since men get what they have asked for, either consensual (de)valued capitalist flesh on the market, whose signifiers are not lost, but hidden away and empowered by each and every sexual experience, or forcefully infringed upon empty bodies, full of contempt, that have been (de)signified by each and every sexual act, which was not based on consensus.

Another key aspect is that, until recently, the industries of pornography and food porn have been capitalistically undergirded, due to their main purpose, that of pushing forward visually appealing imagery for sale. Such an objective has been amplified by media developments which, in turn, have contributed to the financially demanding and avid quest for sexual gratification: "sex consumers are «spacing» or travelling between sites, actual and virtual places, multitasking activities and complicating the commercial thrust of Internet porn sites" (Jacobs 79). Witnessing such an expeditious upgrading of media, it is quite obvious that anyone who has access to Internet can partake, either as consumer or producer of content. Hence, the number of porn sites and blogs has increased dramatically in the past decade, accounting for an oversized pool filled with the same dull pornography, thence "technoporn is becoming increasingly boring in a process 
that opens up new possibilities at the margins of networked sexuality" (Garlick 2). Presented with a variety of porn sites, which are not only architecturally similar, but also include different porn categories, a "fragmentation of pornography on the Internet," a plethora overtakes the viewer, usually a male viewer, since "pornography provides a mirror image of masculinity" (Garlick 2). To put it in Jean Baudrillard's words in "Fatal Strategies":

Sexuality does not vanish in sublimation, repression and morality. It vanishes more effectively in what is more sexual than sex: pornography. The hypersexual is the contemporary of the hyperreal. More generally, visible things do not terminate in obscurity and in silence; they vanish into what is more visible than the visible: obscenity $(1992,188)$.

This kind of image often entails the sexual objectification of women through pornography, an issue in the desiring mechanism(s) of men, which is clearly challenged by Stephanie Sarley's grotesque and quite neoliberal art, by offering the fruit next door and making it materially unattainable.

\section{Stephanie Sarley's Challenging Food Porn}

"Freedom is not a gift received from a State or a leader, but a possession to be won every day by the effort of each and the union of all."

Albert Camus, Create Dangerously $(2018,54)$

Stephanie Sarley's artwork, similarly to that of many present-day artists and influencers, resides on online platforms, such as Instagram ${ }^{3}$ and on a multitude of sites and it can be easily categorized as a form of marginal porn "able to break away from the profit-driven imperative" and to "give us glimpses of sex that rupture the usual narratives of gender and sexuality (...) and potentially disrupt the production of hegemonic masculinity within the pornographic imagination" (Garlick 17), due to its subversive feminist approach to gender inequality.

\footnotetext{
3 Henceforth IG.
} 
Through the use of photography and videography in her art, the artist ironically aims to close the gap between contemplation and assailment, to prove that women are not merely objects of sexual pleasure or mere items to be gazed upon, empty bodies blocked in the vicious and cyclical pattern of gender order.

Owing to the existence of a multitude of postmodernisms and digimodernisms which encompass a large part of the cultural production nowadays, including Sarley's art, it would be wise to stress on Alan Kirby's definition of digimodernism in his 2009 book, Digimodernism, as "the impact on cultural forms of computerization (...) as a cultural shift, a communicative revolution (...) a new form of textuality" (Kirby 50). Kirby established the emergence of the concept in the second half of the 1990s and delineated it from postmodernism, by means of Web 2.0 collaborative uses and productions of knowledge. Paradoxically, the view over his own creation is rather selfcontradictory and superficial, given that he looked over this cultural movement both as an end to the postmodern paradigm and as a continuation of certain postmodern facets into the digimodern's area of cultural domination, as "common sense" and as that "which goes without saying."

Despite Kirby's view, I tend to look at digimodernism as a mix between postmodernism and the development of technology, media and various forms of Web on the Internet, to regard it as a new improved form of postmodernism. What interests me here is the fact that Sarley's art has been published first on IG (2015), and then on her personal website and subsequently exhibited in museums (Jan Cunen Museum, El Segundo Museum of Art, Leipzig Museum of Fine Arts, Cob Gallery London, San Diego Art Institute and SOMA Gallery Berlin) and in various catalogues and magazines, such as Art Magazine Hamburg.

IG, which many of us use, along with other forms of Web 2.0, whether we speak of Facebook, Instagram, Youtube, Reddit, Tumblr, Wikipedia and many others, is inscribed in the digimodern sphere of textuality, due to the fact that other IG users are allowed to tag each other and comment, and even do both simultaneously. The fundamental digimodern text is made up to a varying degree by the viewer, that is by the textual consumer (viewser). He/she somehow 
becomes authorial and intervenes physically in the material textuality, hence the term digital modernism, which has a double pun in our case, as we shall see later.

Related to digimodernism and opposed to its "predecessor" is the (re)birth of the author, a characteristic which uncovers the digital text as having a multiple, yet not a collective authorship, rather a hierarchical one. I refer here to various layers of authorship, starting with the originative level, which is Sarley's, who establishes the parameters, the markers and makes the structural content available to the later, somewhat lower levels, which also produce text that is being consumed by its own authors, by locating and inventing narrative content where none existed. Sarley's artwork on IG is inscribed in the domain of interactivity, because the relationship between the interface of the text and the dialectic of the individual(s) fabricates commutative, diachronic exchanges. This entire catena also inscribes also her art in the sphere of digimodernity and breaks down barriers between the artist and the viewer, by creating alienation through the artifice of the interface. Democratically speaking, the mere logic that the commentaries on her posts did not exist before and the fact that any person can publish anything and be open and non-elitist marginally unites, by way of the interface, the sphere of life, represented by viewers, and art, represented by Sarley's expertise. This, along with the work of art per se, contributes to the ascendancy of a new digital text, whose main characteristic is the timeless, allengulfing and non-spatial trance, a trance which Kirby described in his 2006 essay 4 on the death of postmodernism as "a new weightless nowhere of silent autism".

According to Kirby, the birth of the endless narrative, which also happens to be ultra linear in Sarley's case, raises awareness and conveys the message, which is, in our case, a feminist one. Unlike postmodern texts:

Web 2.0 texts, however, never come to a conclusion. They may stop or be deleted, or fall out of favour [...] but they are rounded-off, not shaped into a sense either of organic coherence or of deliberate open-endedness [...] textual analysis of Web 2.0

4 I refer here to The Death of Postmodernism and Beyond. 
must therefore follow the text in time: it must go with it as it develops, seemingly endlessly, over a lapse of weeks, months, or years. (Kirby 104)

In this line of reasoning, her art, as far as IG is concerned, was and currently is also ephemeral and evanescent, due to the fact that it can disappear at any time and this has happened several times, either when IG deleted her posts for displaying a certain degree of obscenity, or she deleted them herself for various reasons pertaining to the manner in which they were received by the viewers. Again, this ephemerality defines the digital text, because, whatever images or written content you have in a book, they are not that likely to be deleted or to disappear overnight.

Sarley's artwork on IG is also part of the apparently real, but not exactly in Kirby's sense, who mentioned that there is no reality in postmodernism, but in Jean Baudrillard's view of the simulacrum, which he uses as a rather pavlovian argument for his theory. On the other hand, Kirby also regards the apparently real as a negotiation between the viewer and the screen and this very act of negotiating does not apply exclusively to Sarley as an online artist who uploads and updates content, but also to the users. Furthermore, I would argue that, partly, the digimodern reality of Sarley's art consists in the technique of producing art with her own camera, as it resembles an amateur without any sort of artistic background, sometimes with blurred images, off-centred framing, uneven editing, twisted angles, use of natural light and handheld camera shake.

Her art differs from mainstream food porn, not only because of the lack of commercial targets, but also through a variety of postmodern artifices that I will analyse in four works selected from her social media account, artifices which qualify her artistic vision and technique as singular and capable of dismantling the patriarchal gaze, which is actively "producing obsessive voyeurs and Peeping Toms, whose only sexual satisfaction can come from watching, in an active controlling sense, an objectified other" (Mulvey 835), by using the female gaze as a weapon, thus reversing the Freudian castration complex and generating male anxiety. Additionally, Sarley alienates the viewers from the structures implied by gender stereotypes within the performativity of the sexual sphere, because "there 
is no countering of this sexualisation without having that very countering become a sexualized act, precisely by this power of sexual appropriation" (Butler 83).

In one of her famous photographs, one can easily notice the carved inside(s) of a pumpkin, on which milk is being spilled from above, in order to create an effect similar to that of male ejaculation, parodying the climax of masculinity over femininity, which is always rigid and infertile, were it not for the alpha human to impregnate women, flood their vaginas and fulfil their lives with the ambrosia of creation. The fact that the pumpkin is carved to resemble female genitalia hints towards a lack, the lack of a penis, towards the castrated other, whose presence, even objectified as it is, could only be acknowledged by means of her gender counterpart. The process through which the female form gains value could be described as extremely phallic, given the milk spread across the carved form, spilling over its left side and reaching outside, as if intending to surround the vagina, overpowering, silencing and (de)forming it with its powerful, fragmentary and continuous flow of liquid virility.

More notorious is the carved peach photograph entitled "It's My Vagina", which is far more assertive concerning the association with female genitalia, expressly made, both through the title of the artwork and by the visually pronounced resemblances between the female sex and the manner in which various fruits have been displayed in the artistically intended (re)construction. The carved peach displays all the anatomical attributes of the female sexual organ, including the way in which the labial areas parlent femme to the visibly aroused clitoris, which generates the white liquid at the bottom of the fruit, the outcome of female squirting. Moreover, the dimensions of the minor labial areas ironically defy the patriarchal norm and terrify males, due to their oversizing, thus altering the idyllic conception that women's labial zone must be small and must not "hang out", and otherwise their vaginas will be considered ugly and unappealing to men, given their grotesque Bakhtinian way of protruding from the body.

This feminine apex, which begins from under the clitoral area and extends all the way to an absent vaginal opening, passing by the labia minor, along with the visible lack of any "carving", as opposed to the previous photograph, most 
likely seeks to ratify the attainable pleasure in women, without the implication of any male or masculine party in the act and without the act of penetration, per se. “The denial of sexual subjectivity and 'oppressive' experiences include instances where women feel that their sexual selves are confined within a set of parameters" and "do not recognize other possibilities in terms of their sexual lives" (Corsianos 877), being traditionally programmed not to express their sexuality if they wish to maintain their existence and status in the realm of social and of gender, that is the all-encompassing "heteropatriarchal" paradise.

What is quite curious in both photographs is the absence of a domestic context of the art. Sarley used only non-colours, enabling open access and encouraging the self-conscious engagement of the artefact aesthetically, as well as socially inviting the viewers, regardless of their gender, to judge for themselves, creating an alienating breach between observers and the long-preached and fully established societal norms. The viewers should bear in mind that "sexual agency can be defined as the capacity to evaluate and make choices for oneself regarding self-definitions as a sexual being and personal sexual performances regardless of external dominant social forces and social consequences" (Corsianos 865). Unlike the "manuscripts" of mainstream porn, which exhibit women as hollow beings who "do not have an equal voice," Sarley's pornographic script(s) are her own possibly experiential vision on female performativity and cater to all genders, not only to "a predominantly straight male audience" (Corsianos 865).

One could assert the fruitaritarian dimension of Sarley's food porn just by looking at her way of handling grapefruits in one of her numerous video posts, subsequently fragmented into stills and one could also mention that, unlike in the photographs described above, the artist is literally involved into the work of art, suggesting, in a Brechtian manner, through the alienation effect, that the work is only an artefact to be analysed by the viewers. Ironically, this does not stop the social and psychological identification of the viewer with the art, but, on the contrary, it is through this technique of alienation that awareness is raised, giving birth to criticism towards socially and sexually constructed stereotypes and gender roles: "in order to move towards creating possibilities for «sexual agency" for human beings (...) we need to create and promote more diverse forms of 
pornography and make it more accessible to more people" (Corsianos 882-883). Such criticism may enable, among the sensible observers of art, an alienation from one's own gender, not in Denise Riley's linguistic sense: "the more that the category of woman is asserted, whether as glowingly moral and unjustly accused, or as a sexual species fully apart, the more its apparent remoteness from «humanity» is rewritten," $(1995,13)$ but as a self-objective entwining of a visceral and a psychological projection over her/his own gender role(s).

The grapefruit half, which is initially intact and untouched, slightly teased by the finger in its white thin membrane obviously resembles the virgin female sex before penetration by one's fingers. We are clearly shown the gender ambiguous finger going deep inside the grapefruit's core and how it is gradually covered by the trickling juice, which is more similar to the arousing liquid than to defloration blood. This could be the artist's way of sending a message towards patriarchy's fixtures that all virgin women bleed during their first intercourse, or that they do not feel pleasure or arousal, but pain, and that they need a man to open up their path to gratification. On the contrary, one could have another hypothesis regarding the first image, that of a female finger going inside another Venus' genitalia, hence the arousal liquid. The rhythmic movement of the digit is the same in both cases, but merely to underline the ambiguous and multiple dimensions of sexuality and of Sarley's art, as well as the potentiality of challenging the patriarchal confines through postmodern ambiguity.

The same is true for the case when the juicy halves of the grapefruit are symmetrically parted and better contoured by the "hole" created in between them, where the thin membrane with next to no opening used to be, before the continuous and rhythmical insertion of the gender-undefined finger, which is now scattered with one of the same two liquids mentioned above. Whether one chooses to look at the video or at the corresponding photographs, another postmodern challenge arises, that is the lack of a social and of a domestic context in the work of art. This is yet another form of alienation which can be regarded as harking back to Bourdieu's habitus, by taking into account, as I have mentioned in the first part of the paper, that food porn, in its primary form, could not and still cannot be enjoyed by all social classes, due to the fact that such ingredients 
as gold leaf, caviar and lobster, to give an example, were not and still are not accessible to everyone. Such alienation can be classified as a clear demarcation and blurring of boundaries between the spheres of "food porn" and the food porn created by Sarley.

Just by fugitively peaking at the examples discussed above, it is of no doubt that, in creating her art, Sarley also creates a mix between the Baudrillardian simulacrum and Eco's cognition of the concept, both of food porn and of the pornographic sexual act. Through the lack of the original work of art/act, her art is modified by its own commodification through the mechanical reproduction of art. In other words, the long-settled gastronomic boundaries of food porn have been broken once more, by Sarley, in a highly ironic and genderambiguous manner, creating equivocality and giving birth to "hyper-sexual food" in the process. Even so, "hyper-" is not fully hyper-sexual in Baudrillard's sense, as if Sarley's work is not inspired by reality itself and the objects and products she chooses to (de)familiarize in the process of creating are not real, but in Umberto Eco's sense, that of an authentic fake, a "de-" and "re-familiarization" of the food, as the technique employed by the artist is real and singular at the same time. All the fruits and ingredients are perishable, qualifying her work as authentic and unique, given that "in the case of the art object, a most sensitive nucleus namely, its authenticity - is interfered with, whereas no natural object is vulnerable on that score" (Benjamin 4). Due to the entwining of art and food (fruits, other perishable ingredients), one can argue that there is but an intermittent light of the authentic at the end of Sarley's artistic tunnel.

The third artwork abounds in ambiguity and irony. A video in which dough resembling the human posterior is played with, massaged, baked, fingered, buttered and slowly penetrated by a chocolate carrot, until it breaks away for good, akin to pornographic sensibilities. The issue raised in mind is, however, what posterior Sarley is trying to (re)create, either male or female. This gender ambiguous art is completed by the, once again, unclearly gendered and synechdochically presented finger, creating a decidedly variegated mosaic of food porn and sexuality. One could think of a lesbian innuendo, just as much as one male finger could penetrate into another male's back; it could also be a regarded 
as a "feminist" revenge on men or as a "hardcore" heterosexual act of pleasurable sado-masochism.

Given the heterogeneity of possibilities, such postmodern ambiguity challenges Judeo-Christianity's totalizing discourse, which is connotative of concupiscentia carnis and concupiscentia oculorum: "for everything in the world - the desires of the flesh, the lust of the eyes and the pride of life - comes not from the Father but from the world" (1 John 2:16) and of the Sodomico-Gomorral chastising, as far as homosexuality and lesbianism are concerned: "in a similar way, Sodom and Gomorrah and the surrounding towns gave themselves up to sexual immorality and perversion. They serve as an example of those who suffer the punishment of eternal fire" (Jude 1:7), "If a man lies with a male as with a woman, both of them have committed an abomination; they shall surely be put to death; their blood is upon them" (Leviticus 20:13).

Leaving aside the scriptural language, what is quite eye-catching is that, similarly to the grapefruit video, in the dough one the close-up technique on the intromissive scene amounts for a more detailed view of sexuality and pornography, not only in a physical manner, but also in a sensorial and psychological one:

by close-ups of the things around us, by focusing on hidden details of familiar objects, by exploring common place milieus under the ingenious guidance of the camera, the film, on the one hand, extends our comprehension of the necessities, which rule our lives; on the other hand, it manages to assure us of an immense and unexpected field of action. (Benjamin 15)

These hidden details constitute a challenge directed at pornography's metanarrative, due to the fact that Sarley's technique of producing visual pleasure is far more arousing and tantalizing than what is offered by the porn industry with its open bouffet of flesh and yet it causes more outrage and disgust in some of the viewers: "the conventional is uncritically enjoyed, and the truly new is criticized with aversion" (Benjamin 14), while raising awareness towards heteronormativity and patriarchy's iron chains. Such irony seeks to make a 
social-ideological statement with regard to the heterosexual male gaze, which is a rather scopophilic pleasure, and with regard to pornography's heterosexual (pre)dominance.

This is precisely what renders Sarley's art postmodern and turns pornography into a metanarrative for such a subtle and (un)orthodox type of food porn; this power of objectivization beyond the already settled patriarchal limits of sexuality. This fine irony of potentially subjecting males to the who-knows-howsexual gaze of women, thus objectifying them and turning them into the "Other", the petite $b$, forcefully alienating them from their own gender and sexuality and from the age-old ways of enacting them upon women.

The use of the black chocolate carrot alludes and parodies not only interracial sexual relations in pornography and real life situations, but also the male conceit with their endowment(s) and the black man's sexual organ myth, denouncing the racism of social relationships, without overseeing the negative implications and stereotypes concerning the well-known pornographic search category of "black cock/white chick", where manhood and potency are at their highest. Such art may be considered grotesque by individuals who are stuck and blinded by the patriarchal fixture. Sarley's statement is neither to be taken as a radical anti-masculine attitude, nor as a liberal compromise preceding longawaited role change(s), but as an equalizing force, a resuscitation of freedom.

The dimension of corporeality is also expressed through the use of butter, which could be the correspondent of the arousal liquid both in men and women, due to its visibly thick consistency. It could also be considered a subscription to postmodernist art, if one thinks of Bakhtin's view of the abject as that which protrudes from the body, connecting its interior with the exterior. It is also noticeable that such components cannot co-exist with the social component and that if one ignores the inner, i.e. the human self; the outer can be more easily integrated and annexed by the social sphere.

Through this "abject" pharmakon, Sarley militates for the safeguarding and sustaining of female identity, for the destruction of the woman-qua-passive sexual matrix and for the acceptance of the pleasuring bodily reactions that have been denounced both by society and Judeo-Christianity, literally (re)signifying 
the meanings of standardized and stereotyped femininities. Such an acceptance would make it very difficult for patriarchy to hold on to its hegemonic attributes and to exert them over women; it would suspend overly-exaggerated and unchallenged male agency and empower female agency, voicing it in a rather postmodern way, for that is the paradox of the future (post)anterior (modo).

\section{Conclusions}

The freely-circulating pornographic market is resumed to adult websites, which (re)shape sexual performance(s). Pornographic content is offered in exchange for money, unlike Sarley's, and every non-sexual detail is deleted, whether we choose to buy a Playboy magazine or rent a porn movie. Sarley's way of generating art is such that it mimes the mimics and the merging with the online medium, rendering it digimodern as well. By using fruits in order to mime sexual acts, whether abusive or not, sex does not actually happen, there is a lack of partners, a lack of the act, there is only an eroticized fruit and the synechdochical finger/hand paraphernalia. Unsurprisingly, such art is decipherable mainly by attributing it to the male consumer.

The digital capitalist engulfment of Sarley's work of art, despite Lyotard's negative opinion of it as a metanarrative in relation to art, and despite digimodernism's ideology of globalized market economics as a sole and overpowering ruler of all artistic pursuit, Sarley's uploading of aesthetic content on IG, which is a billion dollar company, as well as her exhibitions in various museums, still retain and convey the emancipatory power, share it and make it public, providing social reality through allusions.

By tearing down the borders between bourgeois art and mass culture, in the destroying of the binary Habermasian thought by means of technology, and by blurring the boundaries between artist and amateur by means of Web 2.0, which offers its tools to the unschooled, as much as to the professionals, as well as by increasing Sarley's popularity through the technological distribution and reproducibility of the work of art in the highly populated online medium, I can argue that digimodernism is indeed a part of the technological wing of 
postmodernism, which is alive and well, yet to face many up to the minute "post-" challenges.

Last, but not least, and under a feminist lens, She must understand that there cannot be such a thing as idyllic dreams of freedom which come true in one day and that there are standpoints, laws, traditions and societies to be changed at all times, through hard effort and pain. What we have so far are just small pieces on an empty map, drawn by all those who, before the beginning of our existence, fought hard for every marked meter on that map, subjugated meters which gradually turned into disconnected kilometres of freedom.

Choosing liberal feminism is not, as most think, choosing against radical feminism. On the other hand, liberal feminism is still being chosen today by women who are in horrendous situations, suffering and fighting, but she must know that this is not the only freedom that counts. Both liberal and radical are chosen and must be chosen at the same time, because it is clear that she cannot choose one without the other, but a situational and equilibrated mix of the two positions, as well as an ironic device of subverting, challenging and, hopefully, transcending male-induced institutional oppression(s).

\section{References:}

Baudrillard, Jean, and Mark Poster. Jean Baudrillard: Selected Writings. Stanford University Press, 2001.

---. Simulacra and Simulation. University of Michigan Press, 1994.

Benjamin, Walter. "The Work of Art in the Age of Mechanical Reproduction." Illuminations. Schocken Books, 1969: 1-24.

Bourdieu, Pierre. A Social Critique of the Judgement of Taste. University Press, 1984.

Butler, Judith. Excitable Speech: a Politics of the Performative. Routledge, 1997.

Camus, Albert. Create Dangerously. Penguin, 2018.

Chan, Andrew. "La Grande Bouffe: Cooking Shows as Pornography." Gastronomica, vol. 4, 2003: 47-53.

Cockburn, Alexander. "Gastro-Porn.” New York Review of Books, vol. 24, no. 20, 1977: 5-18. 
Corsianos, Marilyn. “Mainstream Pornography and 'Women': Questioning Sexual Agency." Critical Sociology, vol. 33, no. 5-6, 2007: 863-885, doi:10.1163/156916307x230359.

Debord, Guy. Society of the Spectacle. Aldgate Press, 1983.

Dejmanee, Tisha. “Food Porn' as Postfeminist Play: Digital Femininity and the Female Body on Food Blogs." Television \& New Media, 2015: 1-20.

Docherty, Thomas. "Postmodernism." Jan. 2016: 38-45, doi:10.4324/9781315504612.

Eco, Umberto. Travels in Hyper reality: Essays. Harcourt, 1986.

Garlick, Steve. "Taking Control of Sex?" Men and Masculinities, vol. 12, no. 5, 2009: 1-18, doi:10.1177/1097184x09341360.

Hutcheon, Linda. A Poetics of Postmodernism. History, Theory, Fiction. Routledge, 1988.

---. A Theory of Parody: The Teachings of Twentieth-Century Art Forms. University of Illinois Press. Originally published Methuen, 1985.

Ibrahim, Yasmin. "Food Porn and the Invitation to Gaze." International Journal of E-Politics, 2015: 1-12.

Irigaray, Luce. Speculum of the Other Woman. Trans. Gillian G. Gill. Cornell University Press, 1985.

Kaufman, Fredrick. "Debbie Does Salad: The Food Network at the Frontiers of Pornography." Harper's Magazine, vol. 311, 1865: 55.

Kirby, Alan. Digimodernism How New Technologies Dismantle the Postmodern and Reconfigure Our Culture. Continuum, 2009.

---. "The Death of Postmodernism and Beyond." Supplanting the Postmodern: An Anthology of Writings on the Arts and Culture of the Early 21st Century, doi:10.5040/9781501306907.ch-004.

Kristeva, Julia. Powers of Horror: an Essay on Abjection. Nota, 2017.

Lyotard, Jean François. The Postmodern Condition: A Report on Knowledge. Manchester University Press, 1983.

Magee. R. M. "Food Puritanism and Food Pornography: The Gourmet Semiotics of Martha and Nigella." Americana, vol. 6, no.2, 2007: 1-4. 
Mackinnon, Catherine A. "Sexuality, Pornography, and Method: Pleasure under Patriarchy." Ethics, vol. 99, no.2, 1989: 314-346.

Madison. Alan. Interviewed by Anne E. McBride. "Food Porn.” Gastronomica, vol. 10, no. 1, 2010: 38-46.

Mcbride, Anne E. “Food Porn.” Gastronomica, vol. 10, no. 1, 2010: 38-46.

Mcdonnell, Erin Metz. "Food Porn: The Conspicuous Consumption of Food in the Age of Digital Reproduction." Food, Media and Contemporary Culture, 2016: 239-265.

Mulvey, Laura. "Visual Pleasure and Narrative Cinema." Film Theory and Criticism: Introductory Readings. Eds. Leo Braudy and Marshall Cohen. New York: Oxford University Press, 1999: 833-844.

Ray. Krishnendu. Inerviewed by Anne E. McBride. "Food Porn." Gastronomica, vol.10, no. 1, 2010: 38-46.

Riley, Denise. Am I That Name? Feminism and the Category of "Women" in History. University of Minnesota, 1995.

Rousseau, Signe. "Food 'Porn' in Media." Encyclopedia of Food and Agricultural Ethics, 2013: 748-756, doi:10.1007/978-94-007-6167-4_395-1.

Coogan, D. Michael, et al. The New Oxford Annotated Bible: New Revised Standard Version with the Apocrypha. Oxford University Press, 2010.

\section{Webography:}

Stephanie Sarley. Stephanie Sarley, www.stephaniesarley.com.

---. https://www.instagram.com/stephanie_sarley/?hl=ro (Instagram Account).

---. “Instagram Post by Stephanie Sarley, Nov 30, 2018 UTC.” Instagram, Stephanie Sarley, 2018, www.instagram.com/p/BqyhIX5gKVo/.

---. "Stephanie Sarley on Instagram: 'Carb Craver - behind the Scenes."” Instagram, 2018, www.instagram.com/p/Bh8BR1hAflw/.

---. "Stephanie Sarley on Instagram: “2016". Instagram, 2016, www.instagram.com/p/BYjo5SPhDKi/.

---. 'Stephanie Sarley on Instagram: 'It's My Vagina.' Instagram, 2019, www.instagram.com/p/Bs1GcXOA475/. 